\title{
1 High-order interactions maintain or enhance structural robustness of a coffee agroecosystem \\ 2 network
}

6 Cecilia González González ${ }^{1,2, *}$, Emilio Mora Van Cauwelaert ${ }^{1,3}$, Denis Boyer ${ }^{4}$, Ivette Perfecto ${ }^{5}$, John

$7 \quad$ Vandermeer $^{6}$, Mariana Benítez ${ }^{1 *}$

$9{ }^{1}$ Laboratorio Nacional de Ciencias de la Sostenibilidad, Instituto de Ecología, Universidad Nacional

10 Autónoma de México, Mexico City, C.P. 04510, México

$11{ }^{2}$ Posgrado en Ciencias Biológicas, Universidad Nacional Autónoma de México, Mexico City, C.P.

12 04510, México

$13{ }^{3}$ Posgrado en Ciencias Biomédicas, Universidad Nacional Autónoma de México, Mexico City, C.P.

14 04510, México

$15{ }^{4}$ Instituto de Física, Universidad Nacional Autónoma de México, Mexico City, C.P. 04510, México

$16{ }^{5}$ School for Environment and Sustainability, University of Michigan, Ann Arbor, Michigan, U. S. A.

$17{ }^{6}$ Department of Ecology and Evolutionary Biology, University of Michigan, Ann Arbor, Michigan, U. S.

18 A.

19 *mbenitez@iecologia.unam.mx, ceci_g_g@ciencias.unam.mx 


\section{Highlights}

- The robustness of a coffee-associated ecological network is either increased or unaffected by the incorporation of high order interactions.

- A method is proposed for representing high order interactions in ordinary networks.

- A method is proposed to measure the robustness of networks with high order interactions.

- High order interactions may promote the persistence of diverse ecosystems.

\section{Abstract}

The capacity of highly diverse systems to prevail has proven difficult to explain. In addition to

47 methodological issues, the inherent complexity of ecosystems and issues like multicausality, non-linearity

48 and context-specificity make it hard to establish general and unidirectional explanations. Nevertheless, in

49 recent years, high order interactions have been increasingly discussed as a mechanism that benefits the

50 functioning of highly diverse ecosystems and may add to the mechanisms that explain their persistence.

51 Until now, this idea has been explored by means of hypothetical simulated networks. Here, we test this

52 idea using an updated and empirically documented network for a coffee agroecosystem. We identify

53 potentially key nodes and measure network robustness in the face of node removal with and without

54 incorporation of high order interactions. We find that the system's robustness is either increased or

55 unaffected by the addition of high order interactions, in contrast with randomized counterparts with

56 similar structural characteristics. We also propose a method for representing networks with high order

57 interactions as ordinary graphs and a method for measuring their robustness.

\section{Keywords}

61 Ecological networks, robustness, high order interactions, species coexistence, coffee agroecosystems 


\section{Introduction}

65 The link between an ecosystem's diversity, structure and functioning has long been debated in ecology.

66 Both empirical and theoretical studies have tried to decipher the nature of their relationship and the

67 factors that take part in shaping it. On the one hand, the existence of different definitions for these

68 features has contributed to the difficulty of the task, while on the other hand, an intrinsic complexity

69 stems from the very numerous elements, processes and scales that interact to give rise to these qualities

70 (Ives \& Carpenter 2007). Early ideas on the topic focused on the notion of stability, and maintained that

71 diversity made ecosystems stable through species limiting each others' growth by predation or

72 competition (Odum 1953; MacArthur 1955; Elton 1958). These notions were dramatically challenged by

73 the work of Robert May $(1972 ; 1973)$, who used linear stability analyses to show that communities

74 modelled as random networks lose local stability as the number of species, the number of interactions, or

75 their strength rise. These results caused commotion in the scientific community, as they seemed to

76 contradict the very real biodiversity found around the world. Since then, two main extensions have

77 helped reconcile theory with observation; mainly: the use of realistic community structures (Lawlor 1978;

78 Lawlor 1980) and the complementation of linear stability analyses with other methods to assess

79 ecosystem function from both a structural and a dynamical point of view like robustness, feasibility or

80 structural stability (Landi et al. 2018). It is now generally recognized that diversity tends to positively

81 correlate with some measures of ecosystem functioning, like stability, robustness or productivity.

82 Nevertheless, this does not mean that diversity is the direct driver of these traits, rather, it should be

83 regarded as an 'umbrella' indicator of many ecological mechanisms that are inherent to ecosystems and

84 that are the actual determinants of the diversity-function relationships (McCann 2000). Such mechanisms

85 and how they may favor the assembly and reproduction of highly diverse communities are now the focus

86 of many studies (Chesson 2000; Levine et al. 2017).

87 Different mechanisms have since been proposed to enable the coexistence of species in highly

88 diverse systems (Chesson 2000; Wright 2002; Adler et al. 2013; Levine et al. 2017). Recently,

89 high order interactions (HOI) have been proposed as a key mechanism for the persistence of

90 diverse communities (Bairey et al. 2016, Grilli et al. 2017). A HOI is the effect a species has on

91 the interaction between any other two species. The importance of this kind of interactions has

92 been recognized, as they are quite common: ecosystem engineering, predatory adaptive

93 behavior, changes in foraging, facilitation, mutualisms and many so-called trait-mediated effects

94 commonly involve HOIs (Beckerman et al. 1997; Werner \& Peacor 2003; Holt \& Barfield 2012; 
Kéfi et al. 2012; Bairey et al. 2016). Bairey et al. (2016) computationally explored the role of

96

97

98

99

100

101

102

103

104

105

106

107

108

109

110

111

112

113

114

115

116

117

118

119

120

121

122

123

124

125

HOIs on the linear stability and feasibility of systems described as virtual random networks and found that HOIs could indeed attenuate or even revert a negative relationship between the number of species and stability.

While the findings of Bairey and coworkers (2016) and other recent theoretical work have greatly contributed to our understanding of the relationship between HOIs and species coexistence (Grilli et al., 2017; Singh \& Baruah, 2020; Li et al., 2020), they rely on hypothetical networks whose interactions are set randomly and do not represent known ecological interactions, or on the assessment of some focal species (Mayfield \& Stouffer, 2017). It thus remains unclear how HOIs may affect the function of empirically-documented networks which, arguably, capture some aspects of their structure and dynamics in a more faithful manner. There are now some well-studied ecological and few agroecological networks that could help fill this important gap (Scheffer 1997; Yoon et al. 2004; Fortuna et al. 2014; Perfecto and Vandermeer, 2015; López Martínez 2017). Agroecosystems cover around 40 \% of the Earth's surface (Foley et al. 2005), represent a substantial part of the world's biodiversity, and have just recently begun to be analyzed from a network perspective (Bohan et al. 2013; López Martínez 2017). The insights gained from such a system-level approach hold the potential to guide our actions around major issues like autonomous pest control, disease outbreaks and biodiversity conservation in agricultural landscapes (Vandermeer et al. 2010, 2018; Ramos et al. 2018).

With this in mind, in the present study we updated and analyzed an empirically-based network for a coffee agroecosystem in southern Mexico. This biodiverse agroecosystem has been studied for about three decades and many of its species and interactions have been thoroughly described (Perfecto \& Vandermeer 2015). Importantly, different HOIs have been found to play a key role in the dynamics of the main coffee pests and their natural enemies (Vandermeer et al. 2010; Perfecto et al., 2021), motivating discussions on different formalisms to integrate HOIs to ecological network analyses, which remain an underdeveloped area (Golubski et al. 2016; Battiston et al., 2020). Thus, we analyzed the coffee agroecosystem network from a structural perspective in order to investigate the effects of HOIs on the overall robustness of this system, defined as its capacity to remain connected in the face of node removal representing species loss. 
To this aim, we propose a method for representing networks with high order interactions as ordinary graphs and a method for measuring their robustness which is a modification of Piraveenan et al. (2013). Our work aims to contribute to the understanding of the mechanisms underlying species coexistence in highly diverse systems, as well as to provide novel insights that can inform management practices based on the biological understanding of agroecosystems.

\section{Methods}

The study site is "Finca Irlanda", a 320 ha coffee plantation situated on the highlands of El Soconusco, Chiapas (158110 N, $928200 \mathrm{~W}$; $900 \mathrm{masl}$ ). Precipitation in the region averages $4500 \mathrm{~mm}$ per year and the vegetation type is seasonal tropical forest. Nevertheless, primary vegetation has been almost completely replaced by coffee plantations with different management intensities, aside from some tiny fragments of original forest kept in some farms. In Finca Irlanda, there is a portion of such original vegetation set aside

142 for conservation, while the management of the surrounding productive area involves keeping the shade

143 provided by native trees, which, among other practices, make it a highly biodiverse agroecosystem

144 (Perfecto and Vandermeer, 2015).

145 It is convenient to detail some parts of the complex ecological web found in the study site. There are four 146 main antagonists of coffee plants: the coffee leaf rust, Hemileia vastatrix, the coffee berry borer, 147 Hypothenemus hampei (see Figure 3d further), the coffee leaf miner, Leucoptera coffeella, and the coffee 148 green scale, Coccus viridis (Figure3c). The last one keeps a spatially clustered mutualistic relationship 149 with ants of the Azteca genus (Figure 3e), which feed on the honeydew produced by the scales while 150 protecting them from being eaten by a lady beetle, Azya orbigera. Thanks to this protection, the scale 151 populations reach high levels within the clusters, which in turn increases their probability of being 152 infected by the white halo fungus, Lecanicillium lecanii, a fungus that is also capable of infesting the 153 coffee rust. By patrolling coffee plants where green scales feed, Azteca keeps other herbivores, like the 154 berry borer beetle or the leaf miner from establishing big populations on these plants. However, all the 155 effects that the Azteca ants have on the system are temporally inhibited by flies in the genus Pseudacteon 156 (Family: Phoridae), who are parasitoids of the Azteca ants, and that cause them to retrieve to their nests, 157 hide or dramatically reduce their movement whenever they sense a fly nearby. This inhibition of Azteca 
leaves the scales and the coffee plants unprotected for a period of time, a lapse that has been proven to be ecologically relevant and that for example, is enough for allowing Azya orbigera to prey on the scales or oviposit underneath them, ensuring nourishment for their future larvae (Liere \& Larsen 2010; Vandermeer et al. 2010).

The system here described exhibits different kinds of direct interactions like herbivory and parasitism, but also numerous HOIs (Table S1). For example, Azteca ants exert a second order interaction when they inhibit the predation interaction among $C$. viridis and $A$. orbygera by harrasing the latter, mostly without harming it (Vandermeer \& Perfecto 2006; Liere \& Larsen 2010; Vandermeer et al. 2010). An example of a third order interaction is the effect of the phorid flies, which by paralyzing or chasing away Azteca ants, inhibit the second order interaction they exerted and thus enable the predation of $C$. viridis by A. orbygera

168 (Hsieh et al. 2012).

We used a network approach to analyze the community under study. Species were represented as nodes whose connections were defined by the ecological interactions among them. In order to define the network's structure, we reviewed published information on this particular agroecosystem and integrated

175 it in a common database.

176 The reviewing process began with a book that collects over 20 years of research in the area (Perfecto \& 177 Vandermeer 2015). All referenced papers that explained, observationally or experimentally, at least one 178 ecological interaction among a pair of species, were examined too. The type of interactions and the 179 direction of their effects were extracted, including qualitative information about their strength, whenever 180 available. If any of the papers in this first group made reference to other investigations in the area, those 181 were also revised. All the information was integrated in a database organized as follows: transmitter 182 node (e.g. H. hampei), recipient node (e.g. Coffea), kind of interaction (e.g. +/-), description (e.g. 183 females of $H$. hampei bore into the coffee berries to oviposit and their larvae feed from it) and reference 184 (listing of the articles that support the interaction). For HOIs, instead of a recipient node, a column was 185 added with the recipient interaction (e.g. the presence of Azteca prevents H. hampei from boring into the coffee, inhibiting herbivory). Interactions that were uncertain, but suspected, were annotated but not considered for the construction of the network. Finally, the network was compared with smaller versions published previously and revised by experts. 
The structure of the network was visualized with the software Gephi 0.9.2. Because network-related methods only contemplate ensembles of nodes connected directly through edges (that is, first order interactions), it is not possible to define a network with edges connecting to other edges, which is the case of HOIs. For this reason, two versions of the network were created: the first one only captured the nodes and their first order interactions; the second one included HOI modified interactions as artificial pseudo-nodes, an artifact that allowed us to use the full force of network theory to analyze the system. Topological analyses were conducted on both versions of the network in order to quantify the effect of

\section{HOIs.}

The transformation process of HOIs into pseudo-nodes is depicted in Figure 1. Basically, an edge that was affected by a third node was labeled with a new pseudo-node (e. g. a pseudo-node named 202 "predation"), so the third node had now a simple edge connecting it to the new pseudo-node. The same 203 logic works for second, third or any higher order interactions. A similar procedure was suggested by 204 Newman (2018), where interactions involving more than two nodes are introduced by adding new nodes 205 belonging to a different category as part of a bipartite graph. This new node is connected by a single 206 edge to each original node. However, this procedure is limited as bipartite graphs do not account for 207 edges between nodes belonging to the same category.
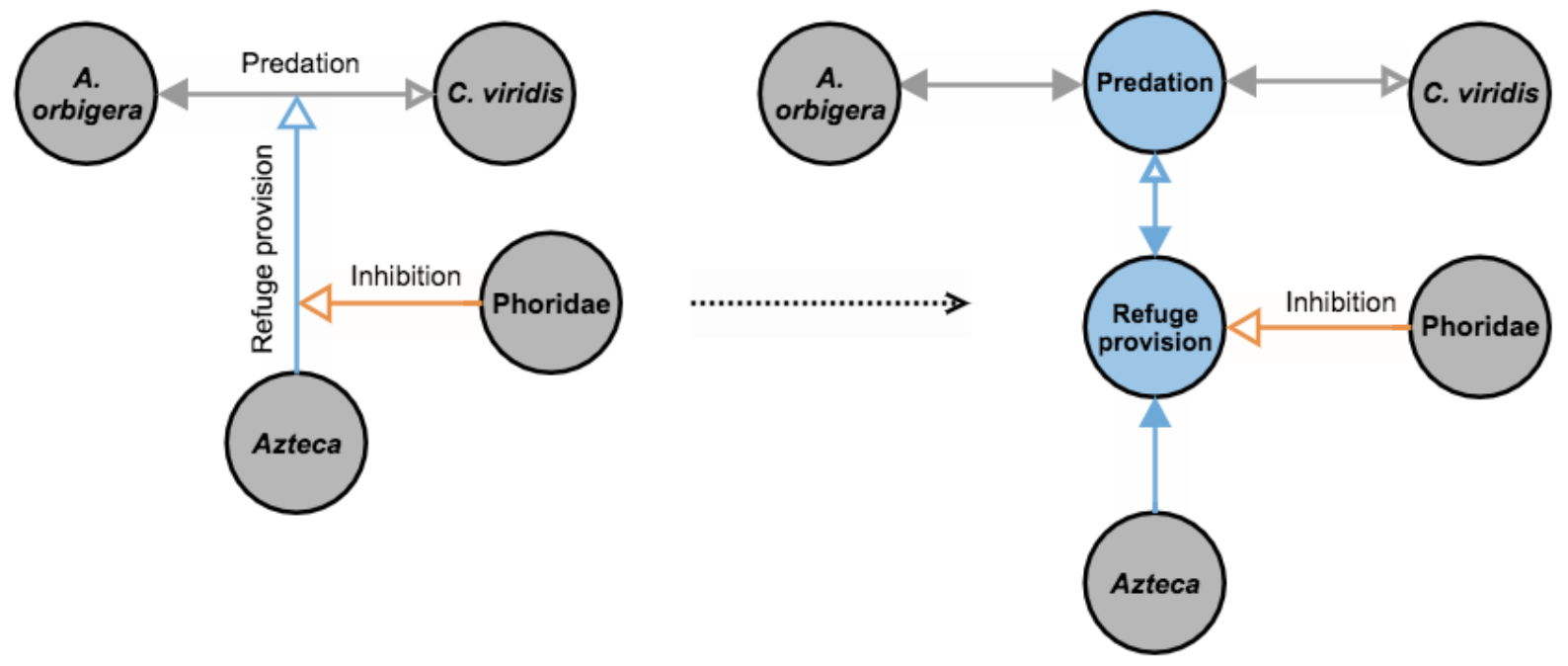
Figure 1. Transformation process of second and third order interactions into pseudo-nodes. The grey nodes represent biological taxa and the blue nodes are pseudo-nodes representing ecological

211 interactions which are modified by a HOI. First order edges are dark grey, second order edges

212 are blue and third order edges are orange. Filled arrows represent positive effects, and unfilled ones,

213 negative effects. For example, the predatory interaction between A. orbigera and C. viridis is turned into

214 a pseudo-node named predation in order to be modified by the refuge provision performed by Azteca, a

215 second order interaction. Likewise, this refuge provision is inhibited by the presence of phorids, so it is

216 turned into a second pseudo-node in order to be modified by the third order interaction performed by

217 Phoridae.

218 Once both versions on the network were obtained, standard network metrics were quantified to 219 characterize them: number of nodes, number of edges, mean degree, diameter, density, modularity 220 (using the Louvain algorithm), clustering coefficient, mean path length, and sigma and omega small 221 world coefficients (Humphries \& Gurney 2008; Telesford et al. 2011). Afterwards, we analyzed node 222 relevance according to their centrality. For this, we used four commonly used metrics: degree, closeness 223 centrality, betweenness centrality, and eigenvector centrality. All calculations were made with the 224 software Gephi 0.9.2.

225

We conducted a robustness analysis for both versions of the network (with and without HOIs). Robustness was measured by calculating the area under the curve that depicts the size of the biggest connected component as nodes are removed one by one from the network (Kasthurirathna et al., 2013; Piraveenan et al., 2013; Navarro Díaz 2015). This measure is compared with the area under the curve traced by a complete graph, that is, a graph where every possible pair of nodes is connected by an edge. Thus, following Equation 1, the relationship between these two areas gives us a measure of robustness (for a full derivation of the equation see Piraveenan et al. (2013)).

$R_{1}=\frac{A_{g}}{A_{c}}(\%)=\frac{200 \sum_{k=0}^{N} S_{k}-100 S_{0}}{N^{2}} \quad \ldots$ Equation 1

236 Where $\mathrm{A}_{\mathrm{g}}$ is the area under the curve of the evaluated graph and $\mathrm{A}_{\mathrm{c}}$ that of the fully connected graph. $S_{k}$ 237 is the size of the largest component after $k$ nodes have been removed, $S_{0}$ denotes the initial largest 
component size, and $N$ is the network size. According to the above equation, for a fully connected network of any size, the robustness coefficient $(R)$ is always of $100 \%$ (taken from Kasthurirathna et al., 2013).

241 For the empirical network that includes HOIs, only real nodes could be selected for removal, in order to 242 avoid the biologically meaningless action of removing pseudo-nodes. Following this logic, whenever a 243 node got selected for removal, any pseudo-node connected to it was also eliminated, since pseudo-nodes

244 lose their meaning once the species causing the higher order effect is eliminated. Because this 245 modification often resulted in the elimination of several nodes at the time, we modified equation 1 in 246 order to control for it. In the Piraveenan et al (2013) derivation, the area under the curve of the fully 247 connected graph assumes one node removal per step in the $x$ axis. If we assume n node removal per step 248 (in order to control for pseudo-node removal in the evaluated graph), this area is $A c=N 2 / 2 n$ and the 249 robustness equation becomes:

$R_{n}=\frac{A_{g}}{A_{c}}(\%)=\frac{200 n \sum_{k=0}^{N^{\prime}} S_{k}-100 n S_{0}}{N^{2}} \ldots$ Equation 2

Where $n$ is the average number of nodes removed at each step (1.54 in this network) and $N$ ' is the number of real nodes in the network ( $N$ minus the number of pseudo-nodes). Equation 1 is equivalent to Equation 2 when $n=1$ and there are no pseudo-nodes.

254 Hence, we used equation 1 for the network without HOIs and equation 2 for the network with HOIs. For each of these networks, two node removal methods were tested. With the first one, nodes were randomly selected and removed one by one until removing them all. This was done 200 independent times and a robustness average was obtained. The second method consisted of removing nodes by degree, from highest to lowest.

The robustness of each network with each removal method was also compared with the average robustness of 200 randomized but comparable networks, i.e. with the same number of nodes, average degree or interaction density. Three types of random networks were used: totally random networks (Erdo $\square$ s \& Rényi 1960), small-world networks (Watts \& Strogatz 1998) and scale-free networks (Barabási \& Albert 1999). The first model generates random networks from a set of nodes in which the edges are independently created between any pair of nodes with a probability $p$. Because the structure of ecological networks is far from being random, we also used small-world and scale-free networks, which have been proved to share structural characteristics with many real world networks (Montoya \& Solé 
lattice where each node is connected to its $k$ closest neighbors, and where each edge is then re-connected to a randomly chosen node with a certain probability, avoiding duplicates and self-loops. This construction produces networks with a high clustering coefficient and short paths, two particularities that have been found in many ecological webs (Montoya \& Solé 2002). The last method builds networks with a preferential attachment mechanism, where nodes are added sequentially such that each new node is connected to a number $m$ of existing nodes, where the probability to choose a node for connection is proportional to the number of links that this node already has. This creates networks with power-law degree distributions, another characteristic that has been widely found in ecological webs (Barabási \& Bonabeau 2003). For the Erdös Rényi method we used the values $N=34$ and $p=0.095$, and $N=22$ and $p=0.145$ for networks representing cases with and without HOIs, respectively (where $N$ is the number of nodes of the empirical web and $p$ is taken from their density). For the Watts-Strogatz method, we chose $N=34, k=3$ and $p=0.5$, and $N=22, k=3$ and $p=0.5$ for networks representing cases with and without HOIs, respectively (where $k$ is the average degree of the empirical web and $p$ was arbitrarily chosen). For the Barabasi-Albert method we chose $N=34$ and $m=1$, and $N=22$ and $m=2$ for networks representing cases with and without HOIs, respectively (where $m$ is chosen so that the resulting average degree matches the empirical average degree).

Because nodes in the empirical network with HOIs were removed along with their associated pseudonodes as discussed above, the randomized versions of this network needed to emulate this process too. This was done in the following way: First, we quantified the probability to remove a number $n$ of pseudo-nodes with each real node removal in 100 simulations of the empirical network with HOIs. Then, in the randomized networks (composed of 34 nodes), a subset of 22 randomly chosen nodes was defined to stand for the real nodes, while the remaining 12 nodes stood for the pseudo-nodes. At each removal step, a node was removed (randomly or by degree as explained above) from the real nodes pool alongside with $n$ nodes from the pseudo-node pool, with $n$ drawn from the probability distribution derived from the mentioned simulations. Again, we used Equation 1 for calculating robustness of the randomized versions of the network without HOIs and Equation 2 for the randomized versions of the network with HOIs. With these numerical experiments we were able to compare, on the one hand, the robustness of the two versions of our network, that is, with and without HOIs, and on the other hand, each empirical robustness with their randomized analogues. Simulations were done with the library NetworkX 2.5 (Hagberg et al. 2008) in Python 3.7.1. and ANOVA tests were performed in RStudio 1.2.1335 (RStudio Team 2020). Scripts are publicly available at: 


\section{Results}

From literature revision, 48 interactions between 22 nodes were established out of 44 scientific papers and books, all conducted in our study site (Figure 2). This information is organized in the supplementary material table $\mathrm{S} 1$.

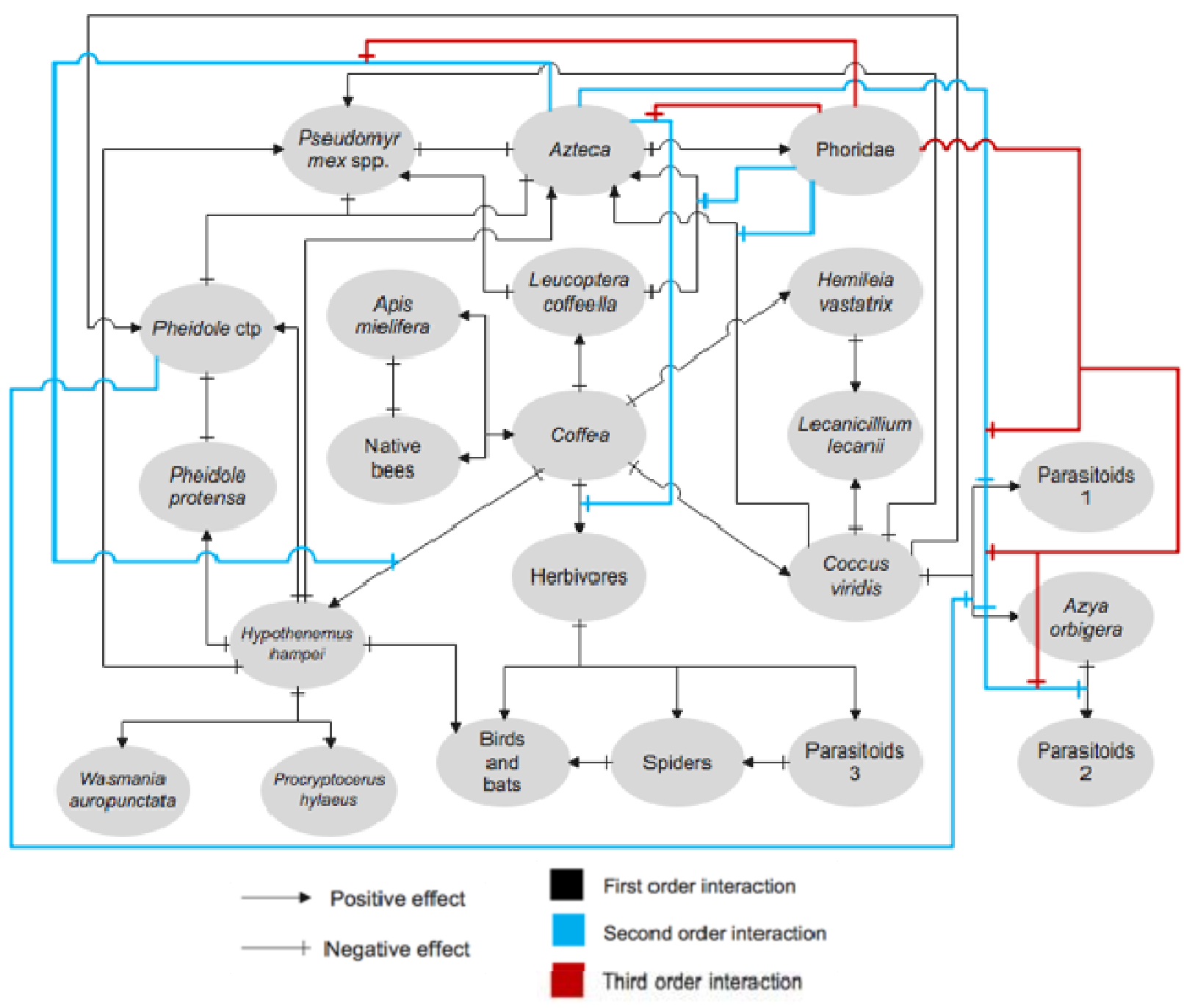

311 Figure 2. Complete network before transformation from HOIs to pseudo-nodes. Black lines are first order 312 interactions, blue lines are second order interactions and red lines are third order interactions. 
316 Two versions of the web were obtained with Gephi, the first one containing only first order

317 interactions and the second one after adding pseudo-nodes for HOIs (Figure 3).
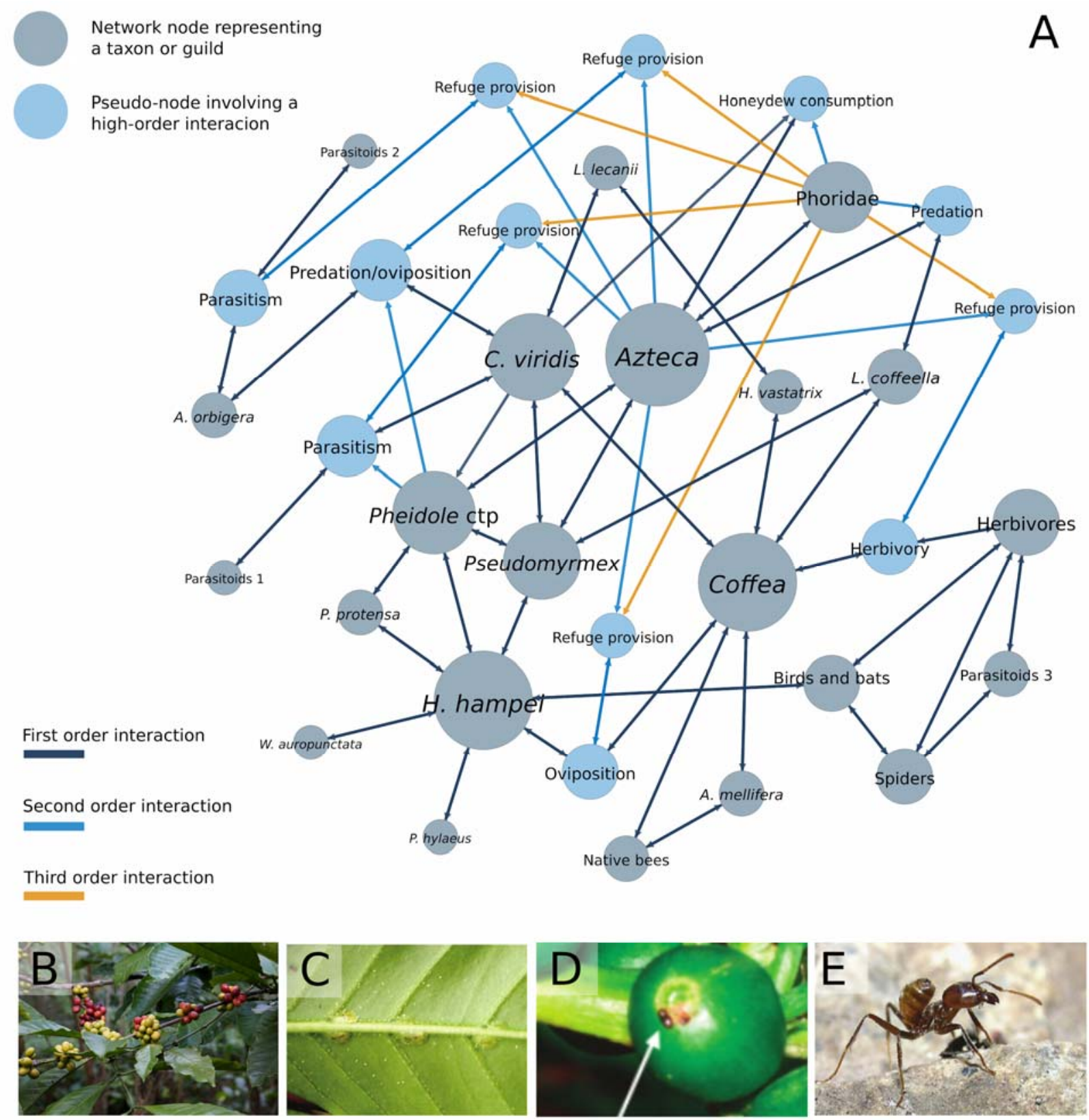

Figure 3. A: Community network with first, second and third order interactions. Grey nodes represent biological taxa and blue nodes are pseudo-nodes representing ecological interactions which are subject to being modified by a HOI. Node size is determined by its degree. First order 
322 edges are grey, second order edges are blue and third order edges are orange. B: Coffee plants

323 (Coffea). C: Coffee green scale (Coccus viridis), a potential pest in the system. D: Coffee berry borer

324 (Hypothenemus hampei), one of the main coffee pests, about to penetrate a coffee grain. E: Azteca ant, an

325 important regulator of this interaction network. Photographs: Wikimedia Commons by Jmhullnot at

326 https://commons.wikimedia.org/wiki/File:CoffeeBerry.jpg (B), John Vandermeer (C, D), Alex Wild (E)

328 Without HOIs, the network is composed of 22 nodes and 68 interactions, while incorporating 329 HOIs makes it a network of 34 nodes and 104 interactions. Both networks have an approximate 330 average degree of 3. Table S2 summarizes the general metrics obtained for both versions of the 331 network. Centrality analysis showed that C. viridis, Coffea, H. hampei, Azteca, Pheidole ctp. and 332 Pseudomyrmex spp are the nodes with the highest rankings in both networks and for different 333 centrality metrics (Figure 4). 
bioRxiv preprint doi: https://doi.org/10.1101/2021.02.22.432328; this version posted February 23, 2021. The copyright holder for this preprint (which was not certified by peer review) is the author/funder, who has granted bioRxiv a license to display the preprint in perpetuity. It is made available under aCC-BY-NC-ND 4.0 International license.

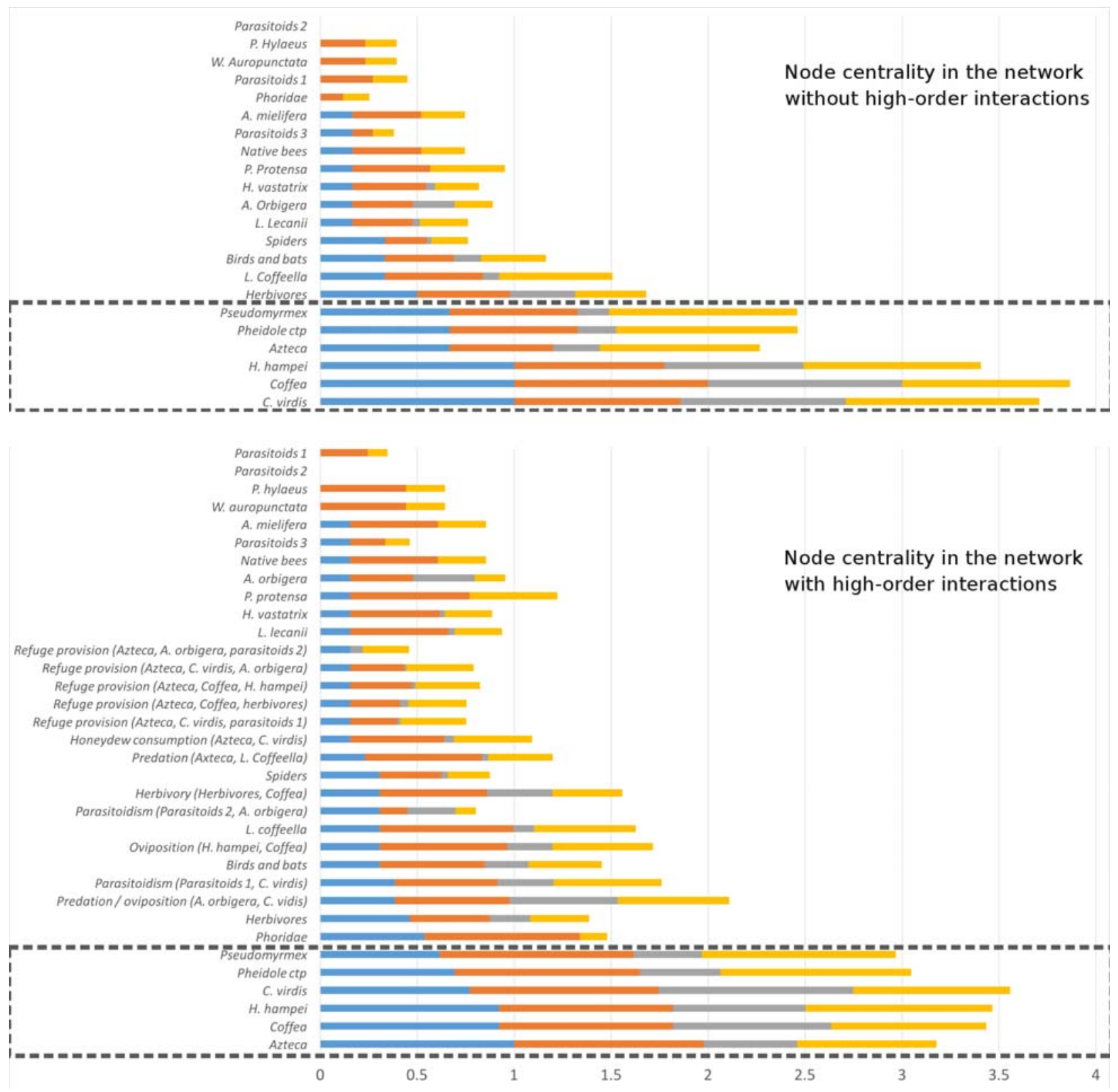

335 Figure 4. Node centrality analysis for the network without HOIs (above) and with HOIs (below).

336 C. viridis, Coffea, H. hampei, Azteca, Pheidole ctp and Pseudomyrmex spp are the highest

337 ranking nodes in both networks.

339 Figure 5 presents the results of the robustness analyses for the empirical coffee networks with 340 and without HOIs, as well as the results for the three different types of randomized networks 341 with comparable structures. In the case of the empirical networks, the addition of HOIs did not 
342 significantly change the network robustness under random node removal, but robustness increased significantly under directed node removal. In contrast, for the three types of randomized networks subject to the two node removal protocols, networks with comparable structures to those with HOI addition significantly lost robustness, except for the completely random networks (Erdos-Renyi) under random removal, which showed no significant changes. Additionally, in the node removal by degree, taking HOIs into account made the empirical network more robust than all its randomized counterparts. Statistical analyses can be found in the table S3 of the Supplementary material. Because all randomized analogues of the network with HOIs have the tendency to lose robustness, while the robustness of the actual empirical networks is either unchanged or increased by HOIs, we can say that the effects observed in the empirical networks are indeed a result of HOI addition and not of simply increasing the number of interactions. Indeed, it seems that high order interactions favor robust network structures that may enable the coexistence of diverse systems.

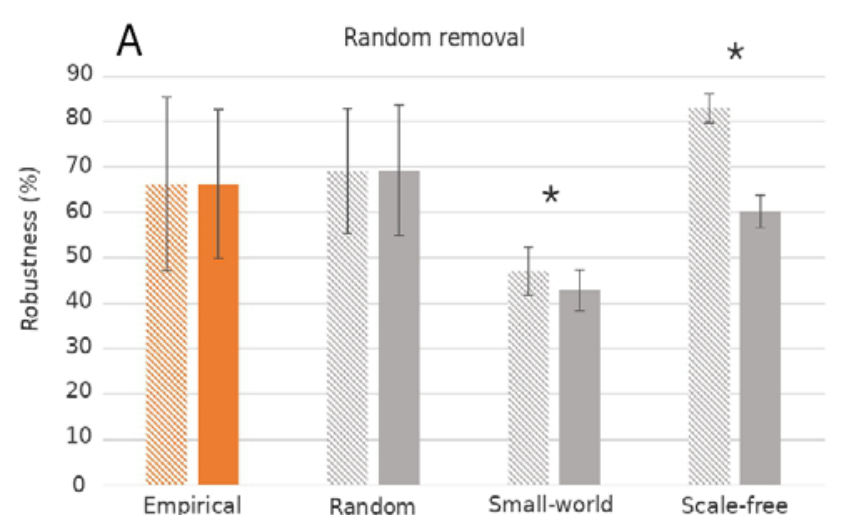

$\mathbb{N}$ Without HOls

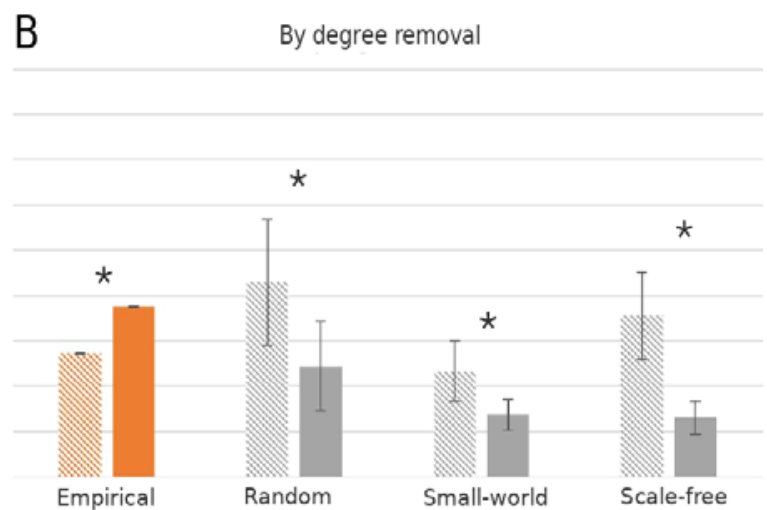

356 Figure 5. Robustness of the coffee-associated network, with and without HOIs, as well as 357 random, small-world and scale free networks with same $n$, mean degree and density. A: Under

358 random node removal, the empirical web (orange bars) and the totally random networks (grey, 359 left) are not significantly changed by the addition of HOIs; while small-world (grey, middle) and 360 scale-free networks (grey, right) loose robustness under HOI addition. B: When removing nodes 361 by degree, the empirical network (orange bars) is significantly more robust when HOIs are 362 added, while the three types of randomized networks (grey bars) lose robustness when their 363 structures are comparable to that with HOI addition. 


\section{Discussion}

We have integrated a vast set of empirical evidence into a coffee-associated network that includes both simple and high order ecological interactions (Figure 3). This network has enabled us to test the role of HOIs on the network's structural robustness for a system of great ecological and agricultural importance. We find that the robustness of the coffee-associated network structure is unchanged or increased by HOI addition, and random reconfigurations indicate that this effect is not simply due to edge addition (Figure measures of system function like stability or feasibility, where the addition of simple interactions has been found to negatively repercute on system function while HOI addition has a neutral or a positive effect (May 1972; Bairey et al., 2016; Grilli et al., 2017; Singh \& Baruah, 2020; Li et al., 2020). ecological communities.

In our study, the structural robustness of the network was evaluated with the change in size of the biggest connected component as the nodes were gradually removed, at random or by targeting nodes of higher degree first. This way of conceptualizing robustness assumes that the connection between network components is related to the function and integrity of the system, implying that a fully connected network can maintain its elements and overall functions better than a disaggregated or partially disconnected network (Albert et al. 2000; Dekker \& Colbert 2004; Piraveenan et al. 2013; Sheykhali et al. 2020). Indeed, previous work on the coffee agroecosystem for which the network under study has been uncovered suggests that some agroecosystemic functions, such as pest control, rely on the dynamics of the whole system and on the documented interactions taking place (Vandermeer et al. 2010). In the particular case of agroecosystems, the integrity of the network, in other words the maintenance of its diversity, is also likely to be associated to yield and yield stability in the face of diverse perturbations (Gaudin et al. 2015; Manns \& Martin 2018).

While the coffee-associated system was studied as an undirected network, the type and sign of its HOIs could inform the mechanism through which HOIs affect the overall robustness. In ecological terms, the HOIs considered in this network may act as buffers of the interactions they modify, thereby diminishing their intensity. For example, refuge provisioning, where one species protects another from one or several predators, may not only explain prey survival (which is important for maintaining the predator), but also 
temporal heterogeneity, may create the necessary conditions for coexistence. However, it is important to bear in mind that individual HOIs may have effects in different directions. Specially in the case of agroecosystems, where effects are measured also in terms of human-based values like productivity, the effect of individual HOIs should not be universally assumed as positive. For instance, it has been shown that the ant Wasmannia auropunctata can indirectly protect the coffee leaf miner against potential predators, potentially limiting the effectiveness of biological control elements (Perfecto et al., 2021).

The structural analyses of the coffee-associated network also allowed us to identify nodes with high centrality according to different metrics (Figure 4). Centrality has been used as an indicator of the role of individual nodes in the overall dynamics of networks; in ecological networks, node centrality is thought to reflect how a node contributes to the flow of energy and matter and ecosystem functioning. Highly central nodes indirectly connect many other nodes in a network and act as 'bridges', a reason why centrality has been amply used in the study of socio-ecosystems networks (Freeman, 1979; Raghavan Unnithan et al., 2014; Lü et al., 2016; Horcea-Milcu et al., 2020; Arroyo-Lambaer et al., 2020). We identified five nodes that systematically exhibited a high centrality, independently of the centrality measure: C. viridis, Coffea, H. hampei, Azteca, Pheidole ctp. and Pseudomyrmex spp. This is in agreement with the crucial role of the coffee plant in this agroecosystem, as well as the effect of its potential pests and pest enemies in its growth and development (Vandermeer et al. 2010). However, at this point we cannot rule out the possibility that the high centrality of these nodes is due to a bias in sampling and research efforts. We are currently pursuing analyses that go beyond the study of the network structure and that might help uncover the role of HOIs and highly central nodes on the dynamics of populations on such a network.

To conclude, our results support the hypothesis that HOIs can contribute to the maintenance and robustness of highly diverse ecological systems, and agroecological systems in particular. In agreement with previous empirical and theoretical studies, our work points to the importance of agroecological management and practices that are based on a deep ecological understanding of productive systems, as well as to the importance of a high diversity of taxons and interactions for the robustness and functioning of agroecosystems.

\section{Funding}


DGAPA-PAPIIT (IN207819). EM acknowledged the graduate program Posgrado en Ciencias Biomédicas, Universidad Nacional Autónoma de México and CONACyT scholarship.

\section{Acknowledgements}

434 The authors thank Blanca Hernández Hernández and Yolanda Robledo Arratia for formatting and figure 435 edition. We also thank members of La Parcela Laboratory and the two reviewers for their valuable 436 comments and suggestions. This article covers part of the requirements to obtain the $\mathrm{PhD}$ Degree in the 437 Posgrado en Ciencias Biológicas de la Universidad Nacional Autónoma de México.

\section{References} mechanisms. Ecology letters 16 (10), 1294-1306. https://doi.org/10.1111/ele.12157.

444 (6794), 378-382. https://doi.org/10.1038/35019019.

Armbrecht, I., Perfecto, I., 2003. Litter ant's diversity and predation potential in two Mexican coffee matrices and forest fragments. Agriculture, Ecosystems and Environment, 97(1-3), 107-115.

Arroyo-Lambaer, D., Uscanga Castillo, A., Piña Tejeda, V. M., Vázquez-Barrios, V., Reverchon, F.,

454 Avelino, J., Willocquet, L., Savary, S., 2004. Effects of crop management patterns on coffee rust

457 Bairey, E., Kelsic, E. D., Kishony, R., 2016. High-order species interactions shape ecosystem diversity. 458 Nature communications 7 (1), 1-7. https://doi.org/10.1038/ncomms12285. 

https://doi.org/10.1038/scientificamerican0503-60

Battiston, F., Cencetti, G., Iacopini, I., Latora, V., Lucas, M., Patania, A., Young, J.G., Petri, G., 2020. Networks beyond pairwise interactions: structure and dynamics. Physics Reports 874, 1-92. https://doi.org/10.1016/j.physrep.2020.05.004 trophic cascade in a terrestrial food chain. Proceedings of the National Academy of Sciences 94, 1073510738. https://doi.org/10.1073/pnas.94.20.10735. 2013. Networking agroecology: integrating the diversity of agroecosystem interactions, in Woodward, D., Bohan, D.A. (Eds.), Advances in Ecological Research. Academic Press, Amsterdam, vol. 49, pp. 1-67.

Chesson, P., 2000. Mechanisms of maintenance of species diversity. Annual Review of Ecology and Systematics 31 (1), 343-366. https://doi.org/10.1146/annurev.ecolsys.31.1.343.

Damon, A., 2000. A review of the biology and control of the coffee berry borer, Hypothenemus hampei (Coleoptera: Scolytidae). Bulletin of entomological research, 90(6), 453-465.

De la Mora, A., Livingston, G., Philpott, S. M., 2008. Arboreal ant abundance and leaf miner damage in coffee agroecosystems in Mexico. Biotropica, 40(6), 742-746.

Dekker, A. H., \& Colbert, B. D., 2004. Network robustness and graph topology, in Estevill-Castro, V. Society, Darlinghurst, NSW, vol 26, pp. 359-368.

Elton, C. S., 1958., Ecology of Invasions by Animals and Plants. Chapman \& Hall, London. 
Erdős, P., Rényi, A., 1960. On the evolution of random graphs. Publications of the Mathematical Institute of the Hungarian. Academy of Sciences 5 (1), 17-60. M.T., Daily, G.C., Gibbs, H.K., Helkowski, J.H., Holloway, T., Howard, E.A., Kucharik, C.J., Monfreda, C., Patz, J.A., Colin Prentice, I., Ramankutty, N., Snyder, P.K., 2005. Global consequences of land use. Science 309 (5734), 570-574. https://doi.org/10.1126/science.1111772.

Fortuna, M. A., Ortega, R., Bascompte, J., 2014. The web of life. arXiv at https://arxiv.org/abs/1403.2575.

Fragoso, D. B., Guedes, R. N. C., Picanço, M. C., Zambolim, L., 2002. Insecticide use and organophosphate resistance in the coffee leaf miner Leucoptera coffeella (Lepidoptera: Lyonetiidae). Bulletin of Entomological Research 92, 203-212. https://doi.org/10.1079/BER2002156 e0113261. https://doi.org/10.1371/journal.pone.0113261.

Golubski, A. J., Westlund, E. E., Vandermeer, J., Pascual, M., 2016. Ecological networks over the edge: hypergraph trait-mediated indirect interaction (TMII) structure. Trends in Ecology \& Evolution 31 (5), 344-354. https://doi.org/10.1016/j.tree.2016.02.006.

Grilli, J., Barabás, G., Michalska-Smith, M. J., Allesina, S., 2017. Higher-order interactions stabilize dynamics in competitive network models. Nature 548 (7666), 210-213. https://doi.org/10.1038/nature23273. 
Hagberg, A., Swart, P., S Chult, D., 2008. Exploring network structure, dynamics, and function using NetworkX, in: Varoquaux, G., Vaught, T., Millman, J. (Eds.), Proceedings of the 7th Python in Science Conference. SciPy Conferences, Pasadena, pp. 11-16.

Hodge, M. A., 1999. The implications of intraguild predation for the role of spiders in biological control. Journal of Arachnology, 351-362.

Holt, R.D., Barfield, M., 2012. Trait-mediated effects, density dependence and the dynamic stability of ecological systems, in: Ohgushi, T., Schmitz, O., Holt, R.D. (Eds.), Trait-Mediated Indirect Interactions: Ecological and Evolutionary Perspectives. Cambridge University Press, New York, pp. 89-106.

Horcea-Milcu, I., Martín-López, B., Lam, D., Lang, D., 2020. Research pathways to foster 25 (1), 13. https://doi.org/10.5751/ES-11332-250113.

Hsieh, H. Y., Liere, H., Soto, E. J., Perfecto, I., 2012. Cascading trait $\square$ mediated interactions induced by ant pheromones. Ecology and evolution 2 (9), 2181-2191. https://doi.org/10.1002/ece3.322.

Hsieh, H. Y., Perfecto, I., 2012. Trait-mediated indirect effects of phorid flies on ants. Psyche: A Journal of Entomology, 2012. canonical network equivalence. PloS one 3 (4), e0002051. https://doi.org/10.1371/journal.pone.0002051.

Ibarra-Núñez, G., Garcia, J. A., López, J. A., Lachaud, J. P., 2001. Prey analysis in the diet of some ponerine ants (Hymenoptera: Formicidae) and web-building spiders (Araneae) in coffee plantations in Chiapas, Mexico. Sociobiology, 37(3), 723-756. https://doi.org/10.1126/science.1133258. promote pattern formation in a tropical agroecosystem. Open Ecology Journal, 2, 62-73. 

management. Oikos, 118(8), 1174-1180.

(Coleoptera: Curculionidae) and its interactions with Azteca instabilis and Pheidole synanthropica (Hymenoptera: Formicidae) in a shade coffee agroecosystem. Environmental entomology, 42(5), 915924.

Johnson, M. D., Kellermann, J. L., Stercho, A. M., 2010. Pest reduction services by birds in shade and sun coffee in Jamaica. Animal conservation, 13(2), 140-147.

Kalka, M. B., Smith, A. R., Kalko, E. K., 2008. Bats limit arthropods and herbivory in a tropical forest.

Science, 320(5872), 71-71.

Kasthurirathna, D., Piraveenan, M., Thedchanamoorthy, G., 2013. On the influence of topological characteristics on robustness of complex networks. Journal of Artificial Intelligence and Soft Computing Research 3 (2), 89-100. https://doi.org/10.2478/jaiscr-2014-0007.

Klein, A. M., Steffan-Dewenter, I., Tscharntke, T., 2003. Fruit set of highland coffee increases with the diversity of pollinating bees. Proceedings of the Royal Society of London B: Biological Sciences, 270(1518), 955-961.

Klein, A. M., Vaissiere, B. E., Cane, J. H., Steffan-Dewenter, I., Cunningham, S. A., Kremen, C.,

592 Tscharntke, T., 2007. Importance of pollinators in changing landscapes for world crops. Proceedings of 593 the Royal Society of London B: Biological Sciences, 274(1608), 303-313.

595 Kremen, C., Williams, N. M., Thorp, R. W., 2002. Crop pollination from native bees at risk from 596 agricultural intensification. Proceedings of the National Academy of Sciences, 99(26), 16812-16816. 
Landi, P., Minoarivelo, H. O., Bra $\square$ nnstro $\square$ m, A $\square$., Hui, C., Dieckmann, U., 2018. Complexity and stability of ecological networks: a review of the theory. Population Ecology 60 (4), 319-345. https://doi.org/10.1007/s10144-018-0628-3. Chiapas, Mexico. Biotropica, 42(3), 342-347. 112 (984), 445-447. https://doi.org/10.1086/283286.

Lawlor, L. R., 1980. Structure and stability in natural and randomly constructed competitive communities. The American Naturalist 116 (3), 394-408. https://doi.org/10.1086/283634. coexistence in complex communities. Nature 546 (7656), 56-64. https://doi.org/10.1038/nature22898.

Li, Y., Bearup, D., Liao, J., 2020. Habitat loss alters effects of intransitive higher-order competition on

612 biodiversity: a new metapopulation framework. Proceedings of the Royal Society B 287(1940), 613 20201571. https://doi.org/10.1098/rspb.2020.1571.

615 Liere, H., Larsen, A., 2010. Cascading trait $\square$ mediation: disruption of a trait $\square$ mediated mutualism by 616 parasite $\square$ induced behavioral modification. Oikos 119 (9), 1394-1400. https://doi.org/10.1111/j.16000706.2010.17985.x.

Liere, H., Perfecto, I., 2008. Cheating on a mutualism: indirect benefits of ant attendance to a coccidophagous coccinellid. Environmental Entomology, 37(1), 143-149. control, 51(1), 51-60. 

complex networks. Physics Reports 650, 1-63. https://doi.org/10.1016/j.physrep.2016.06.007. Ecology 36 (3), 533-536. https://doi.org/10.2307/1929601.

Manns, H.R., Martin, R.C., 2018. Cropping system yield stability in response to plant diversity and soil organic carbon in temperate ecosystems. Agroecology and Sustainable Food Systems 42 (7), 724-750. https://doi.org/10.1080/21683565.2017.1423529.

Mathis, K. A., Philpott, S. M., Moreira, R. F., 2011. Parasite lost: chemical and visual cues used by Pseudacteon in search of Azteca instabilis. Journal of insect behavior, 24(3), 186-199.

May, R. M., 1972. Will a large complex system be stable? Nature 238 (5364), 413-414. https://doi.org/10.1038/238413a0.

Mayfield, M. M., Stouffer, D. B., 2017. Higher-order interactions capture unexplained complexity in diverse communities. Nature Ecology \& Evolution 1 (3), 1-7. https://doi.org/10.1038/s41559-016-0062.

McCann, K. S., 2000. The diversity-stability debate. Nature 405 (6783), 228-233. https://doi.org/10.1038/35012234. 214(3), 405-412. https://doi.org/10.1006/jtbi.2001.2460. Interactions among predators and the cascading effects of vertebrate insectivores on arthropod communities and plants. Proceedings of the National Academy of Sciences, 107(16), 7335-7340.

660 Navarro Díaz, M. 2015. Revisión y análisis comparativo de la estructura ecológica de consorcios

661 procaryotes asociados a biorreactores productores de hidrógeno y de digestión anaerobia. (Bachelor 662 degree thesis). Universidad Nacional Autónoma de México, México, 65 pp. 
Newman, M., 2018. Networks, second ed. Oxford University Press, Oxford.

Odum, E. P., 1953. Fundamentals of Ecology. Saunders, Philadelphia.

Pardee, G. L., Philpott, S. M., 2011. Cascading indirect effects in a coffee agroecosystem: effects of parasitic phorid flies on ants and the coffee berry borer in a high-shade and low-shade habitat.

Perfecto, I., Hajian-Forooshani, Z., White, A., Vandermeer, J., 2021. Ecological complexity and 672 contingency: Ants and lizards affect biological control of the coffee leaf miner in Puerto Rico. 673 Agriculture, Ecosystems \& Environment 305, 107104. https://doi.org/10.1016/j.agee.2020.107104.

675 Perfecto, I., Vandermeer, J., 2006. The effect of an ant-hemipteran mutualism on the coffee berry borer 676 (Hypothenemus hampei) in southern Mexico. Agriculture, Ecosystems \& Environment, 117(2-3), 218677221.

Perfecto, I., Vandermeer, J., 2015. Coffee agroecology: a new approach to understanding agricultural biodiversity, ecosystem services and sustainable development. Routledge, London. 2004. Greater predation in shaded coffee farms: the role of resident neotropical birds. Ecology, 85(10), 2677-2681.

Philpott, S. M., 2005. Trait-mediated effects of parasitic phorid flies (Diptera: Phoridae) on ant (Hymenoptera: Formicidae) competition and resource access in coffee agro-ecosystems. Environmental Entomology, 34(5), 1089-1094.

Philpott, S. M., Greenberg, R., Bichier, P., Perfecto, I., 2004. Impacts of major predators on tropical agroforest arthropods: comparisons within and across taxa. Oecologia, 140(1), 140-149.

693 Philpott, S. M., Pardee, G. L., Gonthier, D. J., 2012. Cryptic biodiversity effects: importance of functional 694 redundancy revealed through addition of food web complexity. Ecology, 93(5), 992-1001. 

robustness of networks under sustained targeted attacks. Social Network Analysis and Mining 3 (4), 939952. https://doi.org/10.1007/s13278-013-0118-8. matrix quality and spatial heterogeneity on biodiversity decline. Ecological complexity 36, 261-267. https://doi.org/10.1016/j.ecocom.2018.10.001.

Raghavan Unnithan, S. K., Kannan, B., Jathavedan, M., 2014. Betweenness Centrality in Some Classes of Graphs. International Journal of Combinatorics 2014, 1-12. https://doi.org/10.1155/2014/241723. http://www.rstudio.com/.

Scheffer, M., 1997. Ecology of Shallow Lakes. Springer Science \& Business Media, Dordrecht.

Schmitz, O. J., Sokol $\square$ Hessner, L., 2002. Linearity in the aggregate effects of multiple predators in a food web. Ecology Letters, 5(2), 168-172. food $\square$ web effects of a devastating predator be reversed?. Ecological Monographs, 72(3), 383-407. M., 2020. Robustness to extinction and plasticity derived from mutualistic bipartite ecological networks. Scientific Reports 10 (1), 1-12. https://doi.org/10.1038/s41598-020-66131-5. 
Telesford, Q. K., Joyce, K. E., Hayasaka, S., Burdette, J. H., Laurienti, P. J., 2011. The ubiquity of smallworld networks. Brain connectivity 1 (5), 367-375. https://doi.org/ 10.1089/brain.2011.0038 epidemiological approach using network theory. European Journal of Plant Pathology 150 (4), 10011010. https://doi.org/10.1007/s10658-017-1339-x.

Vandermeer, J., Perfecto, I., 2006. A keystone mutualism drives pattern in a power function. Science 311 (5763), 1000-1002. https://doi.org/10.1126/science.1121432.

Vandermeer, J., Perfecto, I., 2015. Coffee agroecology: a new approach to understanding agricultural biodiversity, ecosystem services and sustainable development. Routledge.

Vandermeer, J., Perfecto, I., Liere, H., 2009. Evidence for hyperparasitism of coffee rust (Hemileia vastatrix) by the entomogenous fungus, Lecanicillium lecanii, through a complex ecological web. Plant Pathology, 58(4), 636-641.

Vandermeer, J., Perfecto, I., Nuñez, G. I., Phillpott, S., Ballinas, A. G., 2002. Ants (Azteca sp.) as potential biological control agents in shade coffee production in Chiapas, Mexico. Agroforestry Systems, 56(3), 271-276.

Vandermeer, J., Perfecto, I., Philpott, S. M., 2008. Clusters of ant colonies and robust criticality in a tropical agroecosystem. Nature, 451(7177), 457.

Vandermeer, J., Perfecto, I., Philpott, S., 2010. Ecological complexity and pest control in organic coffee production: uncovering an autonomous ecosystem service. BioScience 60 (7), 527-537. https://doi.org/10.1525/bio.2010.60.7.8.

Watts, D. J., Strogatz, S. H., 1998. Collective dynamics of 'small-world' networks. Nature 393 (6684), 440-442. https://doi.org/10.1038/30918.

Werner, E. E., Peacor, S. D., 2003. A review of trait $\square$ mediated indirect interactions in ecological 
764 Williams-Guillén, K., Perfecto, I., Vandermeer, J., 2008. Bats limit insects in a neotropical agroforestry

765 system. Science, 320(5872), 70-70.

766

767 Wright, J. S., 2002. Plant diversity in tropical forests: a review of mechanisms of species coexistence.

768 Oecologia 130 (1), 1-14. https://doi.org/10.1007/s004420100809.

769

770 Yoon, I., R.J. Williams, E. Levine, S. Yoon, J.A. Dunne, N.D. Martinez., 2004. Webs on the Web 771 (WoW): 3D visualization of ecological networks on the WWW for collaborative research and education.

772 Proceedings of the IS\&T/SPIE Symposium on Electronic Imaging, Visualization and Data Analysis 5295,

773 124-132. https://doi.org/10.1117/12.526956.

774

775 Young, G. R., 1982. Recent work on biological control in Papua New Guinea and some suggestions for 776 the future. International Journal of Pest Management, 28(2), 107-114. 
Table S1. Complete database containing all nodes and interactions included in the network, as well as references supporting them.

\begin{tabular}{|c|c|c|c|c|c|c|}
\hline & Source node & Receptor node & $\begin{array}{l}\text { Receptor } \\
\text { interaction }\end{array}$ & $\begin{array}{l}\text { Type of } \\
\text { interaction }\end{array}$ & Description & Reference \\
\hline & Azteca & Coccus viridis & - & $(+/ 0)$ & $\begin{array}{l}\text { Azteca feeds on honewdew secreted by } \\
\text { C. viridis. }\end{array}$ & $\begin{array}{l}\text { Vandermeer \& } \\
\text { Perfecto 2006; Styrsky } \\
\text { \& Eubanks } 2007\end{array}$ \\
\hline & Azteca & $\begin{array}{l}\text { Pseudomyrmex } \\
\text { spp }\end{array}$ & - & $(-/-)$ & Competition, Azteca tends to win. & Vandermeer et al. 2010 \\
\hline & Azteca & $\begin{array}{l}\text { Leucoptera } \\
\text { coffeella }\end{array}$ & - & $(+/-)$ & $\begin{array}{l}\text { Azteca predates L. coffeella, light and } \\
\text { sporadic. }\end{array}$ & $\begin{array}{l}\text { Vandermeer et al. } \\
\text { 2002; Lomeli-Flores et } \\
\text { al. 2009; Vandermeer } \\
\text { et al. } 2010\end{array}$ \\
\hline & Azteca & Phoridae & - & $(-/+)$ & $\begin{array}{l}\text { Phorids are parasitoids of Azteca ants, } \\
\text { causing the death of attacked } \\
\text { individuals and stoping Azteca from } \\
\text { foraging when their presence is sensed. }\end{array}$ & $\begin{array}{l}\text { Philpott 2005; } \\
\text { Vandermeer et al. } \\
\text { 2008; Mathis et al. } \\
\text { 2011; Hsieh \& Perfecto } \\
2012\end{array}$ \\
\hline \multirow{2}{*}{ 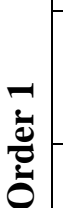 } & Azteca & $\begin{array}{l}\text { Pheidole } \\
\text { synanhropica }\end{array}$ & - & $(-/-)$ & Competition, Azteca tends to win. & Vandermeer et al. 2010 \\
\hline & Azteca & Hypothenemus & - & $(+/-)$ & Azteca predates on $H$. hampei. & Perfecto \& \\
\hline
\end{tabular}




\begin{tabular}{|c|c|c|c|c|c|}
\hline & hampei & & & & Vandermeer 2006 \\
\hline Parasitoids 2 & Azya orbigera & - & $(+/-)$ & $\begin{array}{l}\text { Parasitoids attack A. orbigera and cause } \\
\text { their death. }\end{array}$ & $\begin{array}{l}\text { Liere \& Perfecto 2008; } \\
\text { Vandermeer et al. } 2010\end{array}$ \\
\hline Azya orbigera & Coccus viridis & - & $(+/-)$ & $\begin{array}{l}\text { A. orbygera uses } C \text {. viridis as food or } \\
\text { oviposition place. }\end{array}$ & $\begin{array}{l}\text { Liere \& Perfecto 2008; } \\
\text { Liere \& Larsen } 2010\end{array}$ \\
\hline Parasitoids 1 & Coccus viridis & - & $(+/-)$ & Parasitid wasps attack $C$. Viridis. & Vandermeer et al. 2010 \\
\hline $\begin{array}{l}\text { Hypothenemus } \\
\text { hampei }\end{array}$ & $\begin{array}{l}\text { Pheidole } \\
\text { synanhropica }\end{array}$ & - & $(-/+)$ & $\begin{array}{l}\text { Pheidole ctp predates on } H \text {. hampei. } \\
\text { They are able to replace Azteca on this } \\
\text { function. }\end{array}$ & $\begin{array}{l}\text { Philpott et al. 2012; } \\
\text { Jiménez-Soto et al. } \\
\text { 2013; Vandermeer \& } \\
\text { Perfecto } 2015\end{array}$ \\
\hline $\begin{array}{l}\text { Hypothenemus } \\
\text { hampei }\end{array}$ & $\begin{array}{l}\text { Wasmania } \\
\text { auropunctata }\end{array}$ & - & $(-/+)$ & Wasmania predates on $H$. hampei. & $\begin{array}{l}\text { Gonthier et al. 2013; } \\
\text { Vandermeer \& } \\
\text { Perfecto } 2015\end{array}$ \\
\hline $\begin{array}{l}\text { Hypothenemus } \\
\text { hampei }\end{array}$ & $\begin{array}{l}\text { Pheidole } \\
\text { protensa }\end{array}$ & - & $(-/+)$ & $\begin{array}{l}\text { P. protensa predates on } H \text {. hampei } \\
\text { when the coffee grain falls to the } \\
\text { ground. }\end{array}$ & $\begin{array}{l}\text { Armbrecht \& Perfecto } \\
\text { 2003; Vandermeer \& } \\
\text { Perfecto } 2015\end{array}$ \\
\hline $\begin{array}{l}\text { Hypothenemus } \\
\text { hampei }\end{array}$ & Coffea & - & $(+/-)$ & $\begin{array}{l}\text { H. hampei penetrates coffee grains in } \\
\text { order to oviposit. }\end{array}$ & $\begin{array}{l}\text { Damon 2000; Gonthier } \\
\text { et al. 2013; } \\
\text { Vandermeer \& } \\
\text { Perfecto } 2015\end{array}$ \\
\hline $\begin{array}{l}\text { Hypothenemus } \\
\text { hampei }\end{array}$ & $\begin{array}{l}\text { Pseudomyrmex } \\
\text { spp }\end{array}$ & - & $(-/+)$ & Pseudomyrmex predates on $H$. hampei. & Larsen \& Philpott 2010 \\
\hline Hypothenemus & Procryptocerus & - & $(-/+)$ & P. hylaeus predates on H. hampei. & Vandermeer \& \\
\hline
\end{tabular}




\begin{tabular}{|c|c|c|c|c|c|}
\hline hampei & hylaeus & & & & Perfecto 2015 \\
\hline Coccus viridis & Coffea & - & $(+/-)$ & C. viridis feeds on coffee's fluids. & $\begin{array}{l}\text { Bess 1958; Young } \\
1982\end{array}$ \\
\hline Coccus viridis & $\begin{array}{l}\text { Pheidole } \\
\text { synanhropica }\end{array}$ & - & $(0 /+)$ & $\begin{array}{l}\text { P. synanthropica has a mutualism with } \\
\text { C. viridis like Azteca's, but weaker. } \\
\text { This interaction helps maintain small } \\
\text { colonies of } C \text {. viridis that Azteca can } \\
\text { later use to establish new nests. }\end{array}$ & Vandermeer et al. 2010 \\
\hline Coccus viridis & $\begin{array}{l}\text { Lecanicillium } \\
\text { lecanii }\end{array}$ & - & $(-/+)$ & $\begin{array}{l}\text { L. lecanii infects } C \text {. viridis causing its } \\
\text { death. The probability of infection is } \\
\text { densodependent. }\end{array}$ & Jackson et al. 2009 \\
\hline $\begin{array}{l}\text { Hemileia } \\
\text { vastatrix }\end{array}$ & $\begin{array}{l}\text { Lecanicillium } \\
\text { lecanii }\end{array}$ & - & $(-/+)$ & L. lecanii infects $H$. vastatrix. & Vandermeer et al. 2009 \\
\hline $\begin{array}{l}\text { Hemileia } \\
\text { vastatrix }\end{array}$ & Coffea & - & $(+/-)$ & H. vastatrix infects coffee. & Avelino et al. 2004 \\
\hline Birds and bats & Herbivores & - & $(+/-)$ & Birds and bats predate on herbivores. & $\begin{array}{l}\text { Perfecto et al. 2004; } \\
\text { Kalka et al. 2008; } \\
\text { Williams-Guillén et al. } \\
\text { 2008; Johnson et al. } \\
\text { 2010; Mooney et al. } \\
2010\end{array}$ \\
\hline Birds and bats & Spiders & - & $(+/-)$ & Birds and bats predate on spiders. & $\begin{array}{l}\text { Philpott et al. 2004; } \\
\text { Mooney et al. } 2010\end{array}$ \\
\hline
\end{tabular}




\begin{tabular}{|c|c|c|c|c|c|}
\hline Spiders & Parasitoids 3 & - & $(+/-)$ & Spiders predate on parasitoids 3 . & $\begin{array}{l}\text { Ibarra-Núñez et al. } \\
2001 ; \text { Schoener et al. } \\
2002\end{array}$ \\
\hline Parasitoids 3 & Herbivores & - & $(+/-)$ & Parasitoids 3 attack multiple herbivores. & $\begin{array}{l}\text { Ibarra-Núñez et al. } \\
\text { 2001; Schoener et al. } \\
\text { 2002; Vandermeer \& } \\
\text { Perfecto } 2015\end{array}$ \\
\hline Spiders & Herbivores & - & $(+/-)$ & Spiders predate on multiple herbivores. & $\begin{array}{l}\text { Hodge 1999; Schmitz } \\
\text { \& Sokol-Hessner } 2002\end{array}$ \\
\hline Herbivores & Coffea & - & $(+/-)$ & Multiple herbivores predate on coffee. & $\begin{array}{l}\text { Vandermeer \& } \\
\text { Perfecto } 2015\end{array}$ \\
\hline $\begin{array}{l}\text { Pheidole } \\
\text { synanthropica }\end{array}$ & $\begin{array}{l}\text { Pheidole } \\
\text { protensa }\end{array}$ & - & $(-/-)$ & Competition. $P$. protensa tends to win. & Vandermeer et al. 2010 \\
\hline $\begin{array}{l}\text { Pheidole } \\
\text { synanthropica }\end{array}$ & $\begin{array}{l}\text { Pseudomyrmex } \\
\text { spp }\end{array}$ & - & $(-/-)$ & Competition. Pheidole tends to win. & Vandermeer et al. 2010 \\
\hline Native bees & Coffea & - & $(+/+)$ & $\begin{array}{l}\text { Native bee diversity promotes } \\
\text { pollination and heavier coffee grains. }\end{array}$ & $\begin{array}{l}\text { Kremen et al. 2002; } \\
\text { Klein et al. 2003; Klein } \\
\text { et al. } 2007\end{array}$ \\
\hline Apis mielifera & Native bees & - & $(-/-)$ & $\begin{array}{l}\text { Apis mielifera competes with native } \\
\text { bees and dominates when there is a low } \\
\text { diversity of native shrubs and trees. }\end{array}$ & $\begin{array}{l}\text { Jha \& Vandermeer } \\
2009\end{array}$ \\
\hline $\begin{array}{l}\text { Leucoptera } \\
\text { coffeella }\end{array}$ & Coffea & - & $(+/-)$ & $\begin{array}{l}\text { L. coffeella oviposits on coffee leaves, } \\
\text { harming coffee. }\end{array}$ & $\begin{array}{l}\text { Fragoso et al. 2002; } \\
\text { Lomeli-Flores et al. }\end{array}$ \\
\hline
\end{tabular}




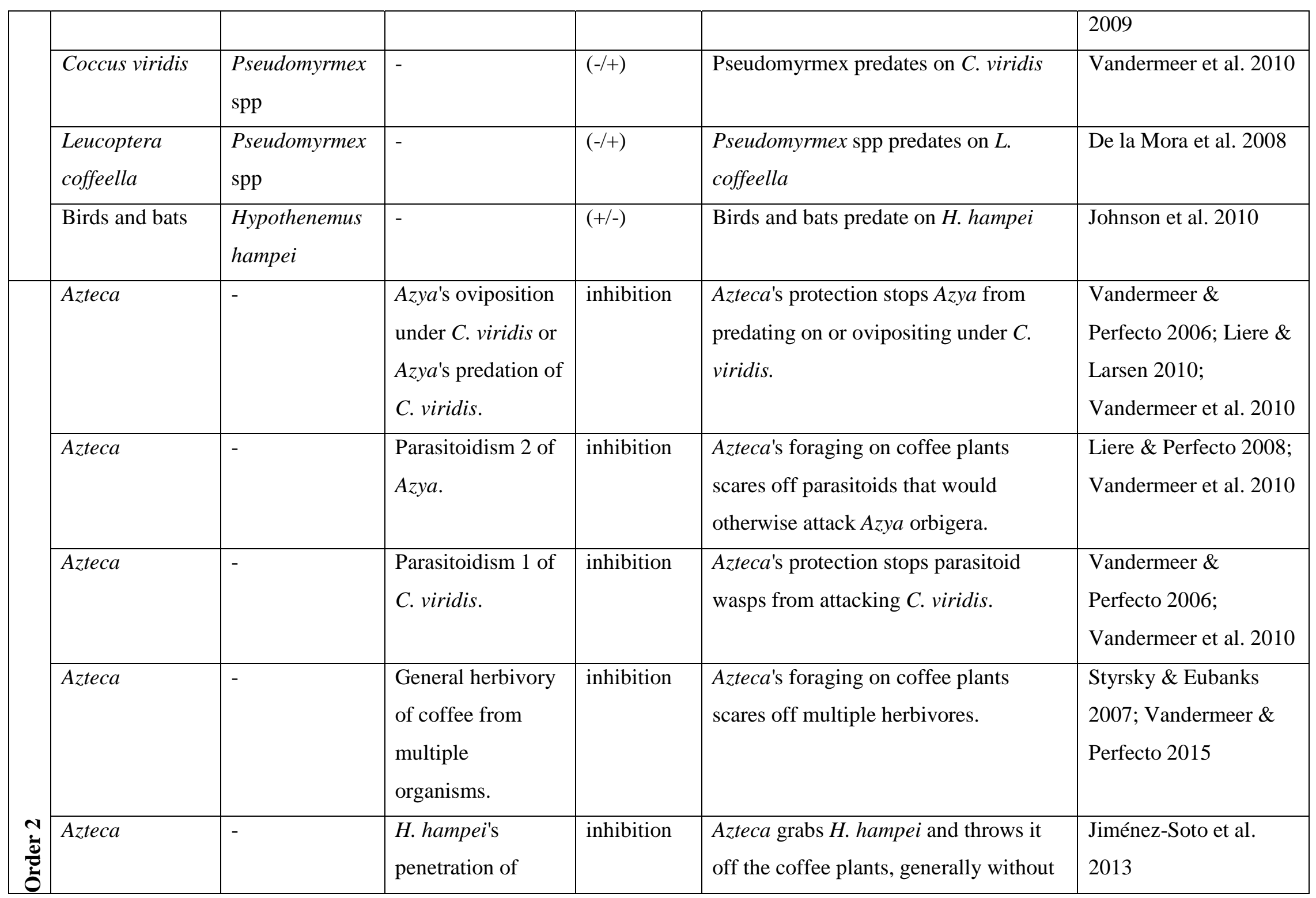




\begin{tabular}{|c|c|c|c|c|c|c|}
\hline & & & coffee grains. & & harming it. & \\
\hline & Phoridae & - & $\begin{array}{l}\text { Mutualism } \\
\text { between Azteca } \\
\text { and } C \text {. viridis }\end{array}$ & inhibition & $\begin{array}{l}\text { The presence of phorids paralizes } \\
\text { Azteca, stoping them from foraging on } \\
\text { C. viridis honeydew. }\end{array}$ & Pardee \& Philpott 2011 \\
\hline & Phoridae & - & $\begin{array}{l}\text { Interaction } \\
\text { between Azteca } \\
\text { and L. coffeella. }\end{array}$ & inhibition & $\begin{array}{l}\text { The presence of phorids paralizes } \\
\text { Azteca, stoping them from predating on } \\
\text { L. coffeella. }\end{array}$ & $\begin{array}{l}\text { Vandermeer \& } \\
\text { Perfecto } 2015\end{array}$ \\
\hline & $\begin{array}{l}\text { Pheidole } \\
\text { synanthropica }\end{array}$ & - & $\begin{array}{l}\text { Azya's oviposition } \\
\text { under C. viridis or } \\
\text { Azya's predation of } \\
\text { C. viridis. }\end{array}$ & inhibition & $\begin{array}{l}\text { P. synanthropica has a mutualism with } \\
\text { C. viridis like Azteca's, but weaker. } \\
\text { This interaction helps maintain small } \\
\text { colonies of } C \text {. viridis that Azteca can } \\
\text { later use to establish new nests. }\end{array}$ & Vandermeer et al. 2010 \\
\hline & $\begin{array}{l}\text { Pheidole } \\
\text { synanthropica }\end{array}$ & - & $\begin{array}{l}\text { Parasitoidism } 1 \text { of } \\
\text { C. viridis. }\end{array}$ & inhibition & $\begin{array}{l}\text { P. synanhropica has a mutualism with } \\
\text { C. viridis like Azteca's, but weaker. } \\
\text { This interaction helps maintain small } \\
\text { colonies of } C \text {. viridis that Azteca can } \\
\text { later use to establish new nests. }\end{array}$ & Vandermeer et al. 2010 \\
\hline & Phoridae & - & $\begin{array}{l}\text { Azteca's inhibition } \\
\text { of parasitoidism } 1 \\
\text { of } C \text {. viridis. ( } 2 \mathrm{nd} \\
\text { order interaction). }\end{array}$ & inhibition & $\begin{array}{l}\text { The presence of phorids paralizes } \\
\text { Azteca, stoping them from inhibiting } \\
\text { wasp parasitoidsm of } C \text {. viridis. }\end{array}$ & $\begin{array}{l}\text { Vandermeer \& } \\
\text { Perfecto } 2015\end{array}$ \\
\hline$\stackrel{m}{\grave{c}}$ & Phoridae & - & $\begin{array}{l}\text { Azteca's inhibition } \\
\text { of coffee }\end{array}$ & inhibition & $\begin{array}{l}\text { The presence of phorids paralizes } \\
\text { Azteca, stoping them from inhibiting }\end{array}$ & $\begin{array}{l}\text { Vandermeer \& } \\
\text { Perfecto } 2015\end{array}$ \\
\hline
\end{tabular}




\begin{tabular}{|c|c|c|c|c|c|}
\hline & & $\begin{array}{l}\text { herbivory from } \\
\text { multiple } \\
\text { organisms. (2nd } \\
\text { order interaction). }\end{array}$ & & $\begin{array}{l}\text { herbivory of multiple organisms on } \\
\text { coffee. }\end{array}$ & \\
\hline Phoridae & - & $\begin{array}{l}\text { Azteca's inhibition } \\
\text { of } H \text {. hampei's } \\
\text { penetration of } \\
\text { coffee grains. (2nd } \\
\text { order interaction). }\end{array}$ & inhibition & $\begin{array}{l}\text { The presence of phorids paralizes } \\
\text { Azteca, stoping them from throwing } H \text {. } \\
\text { hampei off coffee plants. Ants like } P \text {. } \\
\text { symplex and } P \text {. hylaeus are able to } \\
\text { replace this function. }\end{array}$ & $\begin{array}{l}\text { Pardee \& Philpott } \\
\text { 2011; Philpott et al. } \\
2012\end{array}$ \\
\hline Phoridae & - & $\begin{array}{l}\text { Azteca's inhibition } \\
\text { of interaction } \\
\text { between Azya and } \\
\text { C. viridis. (2nd } \\
\text { order interaction). }\end{array}$ & inhibition & $\begin{array}{l}\text { The presence of phorids paralizes } \\
\text { Azteca, stoping them from protecting } C \text {. } \\
\text { viridis from } A \text {. orbigera. }\end{array}$ & Hsieh et al. 2012 \\
\hline Phoridae & - & $\begin{array}{l}\text { Azteca's inhibition } \\
\text { of parasitoidism } 2 \\
\text { of Azya orbigera. } \\
\text { (2nd order } \\
\text { interaction). }\end{array}$ & inhibition & $\begin{array}{l}\text { The presence of phorids paralizes } \\
\text { Azteca, stoping them from scaring off } \\
\text { parasitoids of } A \text {. orbigera. }\end{array}$ & $\begin{array}{l}\text { Vandermeer \& } \\
\text { Perfecto } 2015\end{array}$ \\
\hline
\end{tabular}


792 Table S2. General metrics obtained for the network with and without HOIs.

\begin{tabular}{|l|l|l|}
\hline & Without HOIs & With HOIs \\
\hline Nodes & & \\
\hline & 22 & 34 \\
\hline Edges & & \\
\hline Average degree & 68 & 104 \\
\hline
\end{tabular}




\begin{tabular}{|l|l|l|}
\hline & & \\
\hline Diameter & 5 & 8 \\
\hline & & \\
\hline Density & 0.147 & 0.093 \\
\hline Modularity & & \\
\hline Clustering coefficient & 0.44 (5 modules) & 0.45 (6 modules) \\
\hline Small world coefficient (sigma) & 1.36 & \\
\hline Average path length & 0.334 & 0.261 \\
\hline & & 3.362 \\
\hline
\end{tabular}




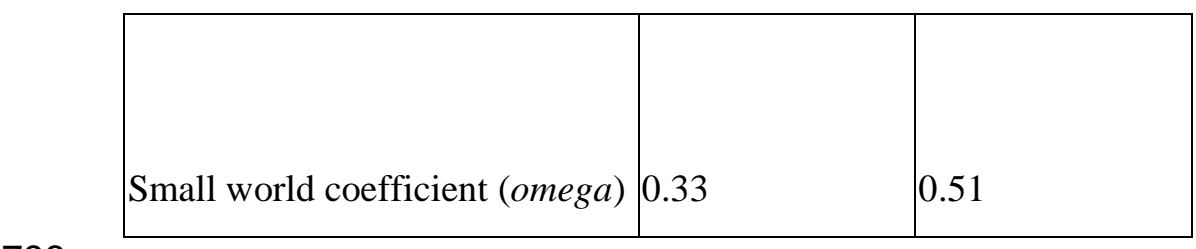

796

Table S3. ANOVA analyses for the robustness of all networks.

807

\begin{tabular}{|l|l|l|l|l|l|l|l|l|l|}
\hline & & $\begin{array}{l}\text { Degrees of } \\
\text { freedom }\end{array}$ & $\begin{array}{l}\text { Sum of } \\
\text { squares }\end{array}$ & $\begin{array}{l}\text { Mean sum } \\
\text { of squares }\end{array}$ & Statistic & $p$ value & $\begin{array}{l}\text { eta square } \\
\text { omega } \\
\text { square }\end{array}$ & $\begin{array}{l}\text { epsilon } \\
\text { square }\end{array}$ \\
\hline $\begin{array}{l}\text { Random } \\
\text { removal }\end{array}$ & $\begin{array}{l}\text { Empirical } \\
\text { with HOIs } \\
\text { vs without } \\
\text { HOIs }\end{array}$ & 1 & 0.019 & 0.019 & 0 & 0.994 & 0 & -0.003 & 0 \\
\hline
\end{tabular}




\begin{tabular}{|c|c|c|c|c|c|c|c|c|c|}
\hline & $\begin{array}{l}\text { Random } \\
\text { with HOIS } \\
\text { vs without } \\
\text { HOIs }\end{array}$ & 1 & 0.014 & 0.014 & 0.17 & 0.68 & 0 & -0.002 & -0.002 \\
\hline & $\begin{array}{l}\text { Small- } \\
\text { world with } \\
\text { HOIs vs } \\
\text { without } \\
\text { HOIs }\end{array}$ & 1 & 1774.66 & 1774.66 & 72.14 & $<0.001$ & 0.153 & 0.151 & 0.426 \\
\hline & $\begin{array}{l}\text { Scale-free } \\
\text { with HOIs } \\
\text { vs without } \\
\text { HOIs }\end{array}$ & 1 & 50986.63 & 50986.63 & 4463.04 & $<0.001$ & 0.918 & 0.918 & 3.349 \\
\hline \multirow[t]{2}{*}{$\begin{array}{l}\text { By degree } \\
\text { node } \\
\text { removal }\end{array}$} & $\begin{array}{l}\text { Random } \\
\text { with HOIS } \\
\text { vs without } \\
\text { HOIs }\end{array}$ & 1 & 34281.86 & 34281.86 & 236.54 & $<0.001$ & 0.373 & 0.371 & 0.771 \\
\hline & $\begin{array}{l}\text { Small- } \\
\text { world with } \\
\text { HOIs vs } \\
\text { without } \\
\text { HOIs }\end{array}$ & 1 & 9312.47 & 9312.47 & 333.91 & $<0.001$ & 0.456 & 0.454 & 0.916 \\
\hline
\end{tabular}

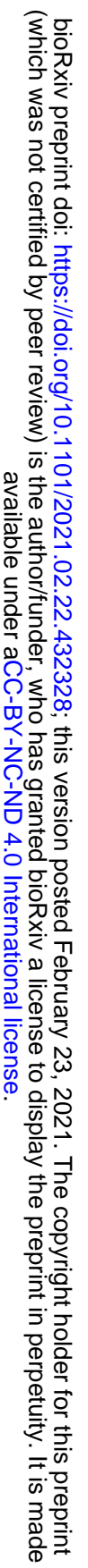




\begin{tabular}{|l|l|l|l|l|l|l|l|l|l|}
\hline & $\begin{array}{l}\text { Scale-free } \\
\text { with HOIs } \\
\text { vs without } \\
\text { HOIs }\end{array}$ & & & 50922.49 & 50922.49 & 964.08 & $<0.001$ & 0.708 & 0.707 \\
\hline
\end{tabular}

809

810

811 